\title{
MOLECULAR PHYLOGENETIC STUDIES ON FILARIAL PARASITES BASED ON $5 S$ RIBOSOMAL SPACER SEQUENCES
}

\author{
XIE H., BAIN O.** ANI) WILLIAMS S.A.*****
}

\section{Summary :}

This paper is the first large-scale molecular phylogenetic study on filarial parasites (family Onchocercidae) which includes 16 species of 6 genera: Brugia beaveri Ash el Litle, 1964 ; B. buckleyi Dissanaike et Paramananthan, 1961 ; B. malayi (Brug, 1927) Buckley, 1960; B. pahangi (Buckley et Edeson, 1956) Buckley, 1960 ; B. patei (Buckley, Nelson et Heisch, 1958 ) Buckley, 1960 ; B. timori Partono et al, 1977; Wuchereria bancroffi [Cobbold, 1877) Seurat, 1921; W. kalimantani Palmieri Purnomo, Dennis and Marwoto, 1980; Mansonella perstans Manson, 1891 ) Eberhard et Orihel, 1984; Loa loa, Stiles, 1905; Onchocerca volvulus (Leuckart, 1983) Railliet et Henry, 1910; O. ochengi Bwangamoi, 1969; O. gutturosa Neumann, 1910; Dirofilaria immitis (Leidy, 1856) Railliet et Henry, 1911 Acanthocheilonema viteae (Krepkogorskaya, 1933) Bain, Baker et Chabaud, 1982 and Litomosoides sigmodontis Chandler, 1931. 5S rRNA gene spacer region sequence dara were collected by PCR, cloning and dideoxy sequencing. The 5S rRNA gene spacer region sequences were aligned and analyzed by maximum parsimony algorithms, distance methods and maximum likelihood methods to construct phylogenetic trees. Bootstrap analysis was used to test the robustness of the different phylogenetic reconstructions. The data indicated that $5 S$ spacer region sequences are highly conserved within species yet differ signifi cantly between species. Spliced leader sequences were observed in all of the 5 S rDNA spacers with no sequence variation, although flanking region sequence and length heterogeneity was observed even within species. All of the various tree-building methods gave very similar results. This study identified four clades which are strongly supported by bootstrap analysis: the Brugia clade; the Wuchereria clade; the Brugia-Wuchereria clade and the Onchocerca clade. The analyses indicated that $L$. sigmodontis and $A$. viteae may be the most primitive among the 16 species studied. The data did not show any close relationship between loa loa and D. immitis presently classified in the same sublamily, and the constitution of the Dirofilariinae subfamily is questionable.

KEY WORDS phylogenetics. ribosomal genes. $5 S$ rDNA. spacers. PCR. molecular cloning. spliced leader sequence. Brugia malayi. B. pahangi. B. fimori. B. patei. B. beaveri. B. buckleyi. Wuchereria bancroffi. W. kalimanIani. Mansonella perstans. Loa loa. Onchocerca volvulus. O. ochengi. $O$. guturosa. Dirofilaria immitis. Acanthocheilonema viteae. Litomosoides sigmodontis.

"Program in Molecular and Cellular Biology, University of Massachusetts at Amherst, Amherst, MA 01003, L. S. A.

**Biologie Parasitaire. Protistologie, Helminthologie, CNRS-LRA 114. Museum d'Histoire Naturelle, 61 rue Buffon, 75231 Paris Cedex 05, France

***Department of Biological Sciences, Smith College, Northampton, MA 01063 , U. S. A

Correspondence: Dr. Hong Xie. Yale Medical School, 100 York

Street. $\neq 4$ A. New Haven, CT 06511 , USA.
Résumé : ÉTTIJES PIITLGÉNÉTIQL'ES MOLÉCILAIRES DES FILAIRES À PARTIR DE SEQI FNCFS DU" "SPACER" DU $5 S$ RIIBOSOMAL

Cette première étude sur la phylogénie moléculaire des filaires (famille des Onchocercidae) - Nématodes chez lesquels les phénomènes de convergence sont particulièrement importants en raison de leur vie fissulaire - inclut 16 espèces appartenant à 6 genres différents: Brugia beaveri Ash ef Little, 1964; B. buckleyi Dissanaike et Paramananthan, 1961 ; B. malayi (Brug, 1927) Buckley, 1960; B pahangi (Buckley et Edeson, 1956/ Buckley, 1960; B. parei (Buckley, Nelson el Heisch, 1958 1 Buckley, 1960; B. timori Partono et al, 1977; Wuchereria bancrofti (Cobbold, 1877) Seurat, 1921; W. kalimantani Palmieri, Purnomo, Dennis et Marwoto, 1980; Mansonella perstans (Manson, 1891) Eberhard et Orithel, 1984; Loa loa Stiles, 1905; Onchocerco volvulus (Leuckart, 1983) Railliet et Henry, 1910; O. ochengi Bwangamoi, 1969: O. gutturosa Neumann, 1910; Dirofilaria immitis (Leidy, 1856) Railliet et Henry, 1911; Acanthocheilonema viteae (Krepkogorkkaya, 1933) Bain, Baker, Chabaud, 1982 et Litomosoides sigmodontis Chandler, 1931. Le gène "spacer" du 5 S rRNA a été collecté, cloné et séquencé par PCR. Les séquences des différentes espèces ont ensuite éré alignées puis leur phylogénie reconstruite par les méthodes de parcimonie, de distance et de vraisemblance. Des analyses de bootstrap ont été utilisées pour tester la robustesse des différentes reconstructions phylogénétiques. Les résut tats indiquent que cette séquence est fortement conservée dans une même espèce alors qu'elle diffère significativement d'une espèce à l'autre. La séquence d'épissure est présente sans variation dans routes les espèces tandis que les régions flanquantes présentent une hétérogénéité même au niveau intra-spécifique. Les différentes méthodes de reconstruction d'arbre présentent quelques contradictions mais elles sont semblables sur plusieurs points et l'étude, très partielle il est vrai comparée d̀ l'abondance des genres et espèces chez les filaires, permet quelques conclusions. 1- le bootstrap soutient fortement quatre clades: le clade Brugia, le clade Wuchereria, le clade Brugia-Wuchereria, le clade Onchocerca; ces clades cor respondent aux genres, ou à des genres très proches, définis par la morphologie classique. 2- Les analyses suggèrent que L. sigmodontis et A. viteae pourraient être les plus primitives des 16 espèces étudiées; cette notion n'est pas en contradiction avec les hypothèses faites antérieurement. 3- Les analyses ne rapprochent pas L. loa et D. immitis, actuellement placés dans la même sous-famille, et la question de la composition des Dirofilarinae se pose.

MOTS CLES : phylogénèse. 5 S rDNA. "spacers". PCR. clonage moléculaire. séquence depissure. Brugia malayi. B pahangi. B. timori. B. patei. B. bea veri. B. buckleyi. Wuchereria bancroffi. W. kalimantani. Mansonella persians. Loa loa. Onchocerca volvulus. O. ochengi. O. gulturosa. Dirofilaria immitis. Acanthocheilonema viteae litomosoides sigmodontis. 


\section{INTRODUCTION}

Fin ilarioid nematodes are a large group of parasites with species of medical or veterinary importance. Numerous detailed morphological and biological studies, pioneered by Wehr (1935), have been conducted in an attempt to clarify the phylogenetic relationships of these parasites (Chabaud and Choquet, 1953; Anderson and Bain, 1976; Chabaud and Bain. 1976). Since convergence phenomena are common in these tissue dwelling parasites, phylogenies derived solely from morphological data maly be misleading. DNA sequence data collected by molecular biological methods provide a new approach in phylogenetic studies. This paper will focus on these molecular data and the results of this study will be compared to those obtained by the classical methods. There were sixteen species of six genera in the Onchocercidae family included in this study : subfamily Onchocercinae: Brugia beateri Ash et Little, 1964 ; B. buckleli Dissanaike et Paramananthan. 1961: B. malay i (Brug, 1927) Buckley, 1960; B. pahangi (Buckley et Edeson, 1956) Buckley, 1960; B. patei (Buckley, Nelson et Heisch, 1958) Buckley, 1960): B. timori Partono et al., 1977 : Wuchereria bancrofti (Cobbold. 1877) Seurat. 1921: W. Kalimantani Palmieri. Purnomo, Dennis and Marwoto, 1980: Mansonella perstans (Manson. 1891) Eberhard and Orihel. 1984; Onchocerca volvulus (Leuckart, 1983) Railliet et Henry, 1910; O. ochengi Bwangamoi. 1969: O. gutlurosa Neumann, 1910: Acantbocheilonema liteae (Krepkogorskalya, 1933) Bain. Baker et Chabaud. 1982 and Litomosoides sigmodontis Chandler, 1931 ; subfamily Dirofilariinae : Loa loa, Stiles, 1905 and Dirofilaria immitis (Leidy, 1856) Railliet et Henry. 1911.

The ribosomal RNA gene spacer regions can be used to infer phylogeny among closely related taxa $(<50$ million years old) (Verbeet et al., 1984; Mclntyre et al., 1988; Yokotal et al., 1989); Gonzale'z et al., 1990 ; Kjems and Garrett, 1990). The 55 rDNA gene spacer region was chosen for this study based on the following three observations: 1 . Filarial parasites may be recently derived (less than 65 million years old. Maggenti, 1983). Therefore, the 5 s rloNA spacer region sequences were likely to possess more phylogenetic information than the ribosomal DNA coding region sequences. 2. The $5 \mathrm{~S}$ rIDNA gene organization was already established for B. malayi. Genomic titration experiments indicated that the Brugia malayi nuclear genome contains about 250 copies of the 5 s rRNA genes (Ransohofff et al, 1989)). In addition, the cletailed organization of $5 S$ genes in nematodes has been studied in C. elegans (Nelson and Honda. 1985). 3. Preliminary data suggested that the coding regions of
58 rIDNA genes were basically identical across all of the filarial species whereas the 58 rDNA spacer region sequences were very well conserved within species, but showed significant variation between species.

\section{MATERIALS AND METHODS}

\section{Filarial parasite. Materials}

T aboratony strains of $B$. pabangi and B. malayi were oltained from Dr. J. McCall (TRS Laboratory. Athens. 1 GA, U.S.A.). B. patei addults were kindly provided by Drs. U.R. Ralo and A.C. Vickery (University of Southern Florida, Gainsville. FL, U.S.A.). B. beatern adults preserved in $100 \mathrm{mM}$ EDTA were kindly provided by Dr. T.C. Orihel (Tulane Lniversity Medical Center, New Orleans, LA, U.S.A.). B. buckle'i adults preserved in $70 \%$ ethanol were kindly provided by Dr. A.S. Dissanaike (Colombo. Sri Lanka). B. timori microfilariae and W kalimantani adults preserved in $100 \mathrm{~m} M$ EDTA were kindly provided ty Dr. F. Partono (Lniversity of Indonesia, Jakarta). Genomic DNA samples of $\boldsymbol{H}$. persicans preserved in ethanol were kindly provided by Dr. S.E.O. Meredith (Amsterdam, the Netherlands). Genomic I)NA samples of Loa loa, I). immitis. $O$. iolv'ulas, A. riteae. and $L$. sigmodontis as well as Loa loa microfilariae were kindly provicled by Drs. T.B. Nutman and E.A. Ottesen (National Institute of Health, Bethesdia, MI), U.S.A.). Genomic DNA samples of $O$. zolvulus, O. ochengi and $O$. gutturosa were kindly provided by Dr. T.R. Innasch (University of Alabama at Birmingham. Birmingham. AL, U.S.A). Morphological analyses were conducted to verify the identity of some specimens.

\section{EXPPRIMENTAL PROCFIDIRES}

\section{Extraction of parasite DNA}

Individual adult filarial parasites were picked from $70 \%$ ethanol solution and evaporated to dryness. The worms were resuspended in $50 \mu \mathrm{H} \mathrm{H}_{2} \mathrm{O}$ and boiled for 10 minutes. These preparations were used as the PCR templates. Similar treatment was performed for $B$. timori and Loa loa microfilariae, and for $W$. Ralimantami and B. beateri adult worms which were preserved in $100 \mathrm{~m} .1 \mathrm{I}$ EDTA. This treatment was not necessary for those species whose genomic DNA was alreacly available (except the IDNA sample of 11 . perstans which was preserved in ethanol). These genomic IDNA samples were used directly in the PCR reactions. The DNA sample of $M$. perstans was evaporated dry from an original

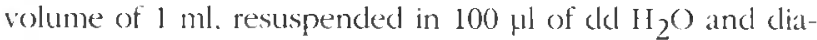
lyzed against $0.05 \mathrm{x}$ TE buffer for four hours before it was used for PCR realctions.

Amplification of $5 \mathrm{~S}$ rDNA sequences from parasite I)NA

The polymerase chain reactions (PCR) rere conducted using Perkin-Elmer-Cetus 480 and system 9600 thermal 
cyclers. Two primers matching the coding region of the $B$ malayi 5 S rIDNA gene were custom synthesized by the I) NA oligo nucleoticle service of the Program in Molecular and Cellular Biology, University of Massachusetts (Amherst, MA. U.S.A.). The sequences of the two primers were:

Primer $\$ 2$ : 5'-GTTAAGCAACGTTGGGCCTGG-3';

Primer $\$ 16$ : 5'T"IGACAGATCGGACGAGATG-3'.

All PCR reagents except primers, template and double distilled water $\left(\mathrm{dd}_{2} \mathrm{O}\right)$ were from the GeneAmp PCR kit purchased from Perkin-Elmer Cetus (Norwalk. CT). The PCR reaction contents included : $5 \mu \mathrm{l}$ of $10 \mathrm{x}$ reaction buffer, $8 \mu \mathrm{l}$ of $1.25 \mathrm{mM}$ dNTP mixture, 20 pmoles of each primer, 1-2 $\mu \mathrm{l}$ template DNA solution. 1 unit of Taq polymerase and dd $\mathrm{H}_{2} \mathrm{O}$ added to a total volume of $50 \mu \mathrm{H}$. The PCR cycling programs used were: $93^{\circ} \mathrm{C}, 1$ minute; $55^{\circ} \mathrm{C}, 1$ minute: $72^{\circ} \mathrm{C}$, 1 minute for a total of 30 cycles (Model 480 thermal cycler); and $93^{\circ} \mathrm{C}, 30$ seconds; $55^{\circ} \mathrm{C}, 30$ seconds; $72^{\circ} \mathrm{C}, 30$ seconds for a total of 30 cycles (System 9600 thermal cycler).

Cloning of the PCR amplified $5 \mathrm{~S}$ rDNA spacer region sequences

The TA cloning system from Invitrogen Corporation (San Diego, CA) was used to clone the $5 \$$ rDNA PCR products. All of the reagents needed for ligation (except the amplified is rDNA products) were provided in the TA cloning kit. The manufacturer's protocols were strictly followed. Recombinant Escherichia coli colonies (white colonies) were picked with a sterilized platinum wire loop and screened by PCR using the same primer pairs as in the original PCR amplification. The loop of $E$. coli cells was placed directly into the PCR reaction tube. The PCR program was the same as for the original $5 \mathrm{~s}$ rloNA amplification except the reactions were incubated in the thermal cycler at $95^{\circ} \mathrm{C}$ for five minutes to burst the cells before the initiation of the 30 cycles. The PCR products were run on $1.5 \%$ agarose gels and stained in ethidium bromide to identify positive clones.

\section{Plasmid DNA preparation and purification}

Individual $E$. coll clones with 55 rDNA inserts were inoculated into $20 \mathrm{ml}$ of LB medium containing $50 \mu \mathrm{g} / \mathrm{ml}$ of kanamycin and incubated at $37^{\circ} \mathrm{C}$ with vigorous shaking overnight. The cells were harvested the next morning by centrifugation at $5,000 \mathrm{~g}$ for ten minutes. The cell pellets were resuspended in PI buffer from the Plasmid Midi Kit and plasmid DNA was isolated following the manufacturer's protocol [Qiagen Inc. (Chatsworth. CA. U.S.A.)]

\section{DNA secpuencing}

The DNA sequencing primers used were primers $\$ 2$ and $\$ 16$ as described before and the M13 universal sequencing primers (primer 1201 and 1211 from New England Biolabs, Beverly, MA, U.S.A.). The CircumVent Thermal Cycle Sequencing Kit from New England Biolabs was used to sequence the plasmid IDNA. The manufacturer's protocols for thermal cycle sequencing with labeled $35 \mathrm{~s}$ (IATP incorporation were followed. $35 \mathrm{~S}$ dATP was purchased from Amersham Corp. (Arlington Heights, IL, LSA). About 200 ng of plasmid IDNA and 2 pmol of primer were used for each sequencing reaction. All of the other reagents were provided in the kit. The Perkin Elmer Cetus thermal cycler 480 wals used with the following program : $95^{\circ} \mathrm{C}, 20$ seconds; $55^{\circ} \mathrm{C}, 20$ seconds; $72^{\circ} \mathrm{C}, 20$ seconds for a total of 20 cycles.

\section{Sequence Data Analysis}

\section{Sequence alignment}

The Pileup computer program from the GCG package (Genetics Computer Group. Inc. Madison, WI, USA) was used to align all of the $5 \mathrm{~S}$ rDNA sequences. Because more than one $5 \mathrm{~S}$ rDNA spacer region sequence was obtained for each species, pileup was used first to align the multiple sequences from the same species. The gap penalty (penalty for opening a gap) was set to two and gap length penalty (penalty for each character space in the gap) was set to zero. Another program in the GCG package, Pretty, was used to print out consensus sequences for each species. Any site that had more than $40 \%$ of a nucleoticle other than the major nucleotide was considered polymorphic and ILPAC-ILB nucleoticle notations were used. The final consensus sequences of all the sixteen species were then aligned by the pileup program. Only the portion of the sequences that were well aligned were selected for further analysis.

\section{Phylogenetic reconstruction from sequence clatá}

PAUP 3.1 (Phylogenetic Analysis Using Parsimony, Swofford, 1993) was used for phylogenetic tree reconstruction (Swofford and Olsen, 1990). Characters were treated as unordered (Fitch, 1971) and were equally weighted. Gaps were treated as missing data. The exhaustive search option was used on ten of the sixteen species. The branch-andbound algorithm was used for the full set of 16 species. Bootstrap analysis was used with PAUP 3.1.

PHYLIP 3.5c (Phylogeny Inference Package, Felsenstein, 1993) was also used for data analysis. Maximum likelihood algorithms (Felsenstein, 1981) and clistance methods (Neighbor-joining algorithm, Saitou and Nei, 1987) were used in the analyses. Bootstrapping analysis was also used with the PHYLIP package to estimate confidence intervals in the phylogenetic trees.

All of the PALP computation and some of the PHYLIP distance method analyses were done using a Macintosh SE-30 and a Macintosh IIci computer. Sequence alignment. maximum likelihood analyses, and bootstrap analyses (except bootstrap with PAUP) were done on a Sun Sparc workstation running sun OS 4.1.1 located in the Iniversity of Massachusetts at Amherst. 
Constant :

$\begin{array}{lrlll}* & * & * * * & \\ * * * * * & * * & * & * * *\end{array} * * *$

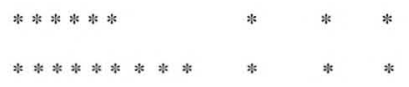

Uninf.

B.malayi

B.timori

B.beaveri

B.patei

B.pahangi

B.buckleyi

Loa loa

M.perstans

O.ochengi

O.volvulus

O.gutturos

W.bancroft

W.kalimant

D.immitis

A.viteae

L.sigmodon

A.lumbrico

AGCTGAATGTTGAATACACAACAACTATATGATA - . . - ATGATGCAGGTATGATCGAC AGCTGAATGTTGAATACACAACAACTATATGATA - - - - ATGATGCAGGTATGATCGAC AGCTGAATGTTGAATACACAACAACTATATGATA - . - . ATGATGCAGGTATGATCGAC AGCTGAATGTTGAATGCACAACAACTATATGATA - - - - ATGATGCAGGTATGATCGAC AGCTAAATGTTGAATGCACAACAACTATATGATA - - - - ATGATGCAGGTATGATCGAC AGCTGAATGTTGAATGCACAACAACTAGATGATA - . - . ATGATGCAGGTATGATCGAC CGATGATTATTGAATGCACGACAATGATATGAAA - - - - A ATGATGAAGTTAGA TTTGAC CGTTGATATTTGAATGCACGACAATGATATGTGA - - - - ATGATGATGGTGTRCACGTC TAATTATTTTYGRATGYACAACAGTCATATGAGA- - - - ATGAAGTAGTTACAAACATT TAATTAT T TTT GAATGTACAACAGTCATATGAGA - - - - ATGAAGTAGTTACAAACAT T TAATTATT TTT GAATGCACAACAGTCAGATGAGA - - - - ATGGAGTAGTTRCAWACAKT TGATGAATGTTGAATGCACAACAACTATATGGGA - . - . ATGGTGCAGGTAGGATCACC TGATGAATGTTGAATGCACAACAACTATATGGGA - - - - ATGATGCAGGTAGAATCACC AAGCCATTT TTCGATGCACTAAAATGATATATGA - - - - ATGAAGCAAT GATATTTGAC CAACYATTGTTGAATGCAGCACAAACGTATCAGC - . - . GTGTTGGGGTTGCATTCCAC CACCGATCGATGGATGCAGCACAACCATAACTAC - - - - ACGATGCGGATGAGGTCGTC GGGAAATGATTGAATGTGATA CTCGTTTTTGCAC TTACCGATTG TGGGGA TGATCTCGAT

Constant: $* * * * * * * \quad * \quad * * * * * * * * * * * \quad * * * * \quad * * \quad * * * \quad * * * * * \quad * * * * * * \quad * \quad * \quad * \quad *$

Uninf. : $* * * * * * * * * * * * * * * * * * * * * * * * * * * * * * \quad * * * * * * \quad * * * * * * \quad * * * * * * * * \quad * \quad * * \quad *$

B.malayi

B.timori

B.beaveri

B.patei

B.pahangi

B.buckleyi

Loa loa

M.perstans

O.ochengi

O.volvulus

O.gutturos

W.bancroft

W. kalimant

D.immitis

A.viteae

L.sigmodon

A.lumbrico

Constant :

Uninf. :

B.malayi

B.timori

B.beaveri

B.patei

B.pahangi

B.buckleyi

Loa loa

M.perstans

O.ochengi

O.volvulus

O.gutturosa

W.bancrofti

W. kalimantani

D.immitis

A.viteae

L.sigmodontis

A.lumbricoides
GGTTTAATTAYCCAAGTTTGAGRTAATTGAATGTTTCGGCCCAGAG - - - TTTAGGCTAC GGTTTAATTACCCAAGTTTGAGGTAATTGAATGTTTCGGCCCAGAG - - - - TTTAGGCTAC GGTTTAATTACCCAAGTTTGAGGTAATTGAATGTTTCGGCCCAGAG - - - TTTAGGCTAC GGTTTAATTACCCAAGTTTGAGGTAATTGAATGTTTCGGCCCAGAG - - - TTTAGGCTAC GGTTTAATTACCCAAGTTTGAGGTAATTGAATGTTTCGGCCCAGAG - - - TTTAGGCTAC GGTTTAATTACCCAAGTTTGAGGTAATTGAATGTTTCGGCCCAGAG - - - TTTAGGCTAC GGTTTAATTACC\&AAGTTTGAGGTAATTGAATGTTTCGGCCCAGAG - - - TTTCGGCTAC GGTTTAATTACCCAAGTTTGAGGTAATTGAATGTTTCGGCCCAGTG - - - TTTCAGCTAC GGTTTAATTACCCAAGTTTGAGGTAATTGAATGTTTCTGCCCAGAG - - - TTTCGACTGC GGTTTAATTACCCAAGTTTGAGGTAATTGAATGTTTCTGCCCAGAG - - - TTTCGACTGC GGTTTAAWTRCCCAAGTTTGAGGTAATYKAATGYTTCAGCCCAGAG - - - - TTTMGAMTGC GGTTTAATTACCCAAGTTTGAGGTAATTGAATGTTTCGGCCCAGAG - - - TTTAGGCTAC GGTTTAATTA SCCAAGTTTGAGGTAATTGAATGTTTCGGCCCAGAG - - - TTTAGGCTAC GGTTTAATTACCCAAGTTTGAGGTAATTGAATGTTTCAGCCCAGAA - - - TTATA TCTGC GGTTTAATTACCCAAGT'T'TGAGGTAATTGAATGTTTCGGCCCAGAG - - - TTTCGGCTGC GGTTTAATTACCCAAGTTTGAGGTAATTGAGTGTTTCGGCCCAGAG - - - TTTCGGCTTC GGTTTAATTACCCAAGTTTGAGGTAATTCCGTGTTTCAGCTCAGTGCTTC TATCGGCT-C 22 -nt spliced leader sequence

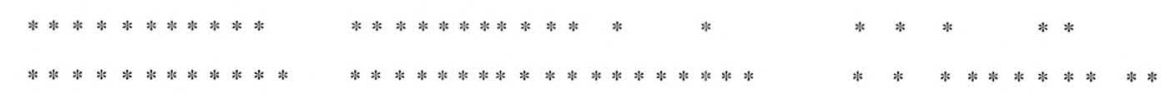

TGTGGCTTGAAGTAAAATTTTGGAACGTCCTGCATATTTGTGGGACAATAA TGTGGCT'TGAAGTAAAAT'T'T'TGGAACGTCCTGCATATTTGTGGGACAATAA TGTGGCTTGAAGTAAAATTTTGGAACGTCCTGCATAATTGTGGGACAATAA TGTGGCTTGAAGTAAAATTTTGGAACGTCCTGCATATTTGTGGGACAATAA TGTGGCT"TGAAGTAAAATTTTGGAACGTCCTGCATATTTGTGGGACAATAA TGTGGCTTGAAGTAAAATTTTGGAACGTCCTGCATATTTGTGGGACAATAA TGTGGCTTGAAGTAAAATTTTGGAACGTCCTGCAAT'TTTGTGGGACAACAA TGTGGCTTGAAGTAAAATTTTGGAACGTCCTACAAATTTGTGGGACAACAA TGTGGCTTGAAGCGAAATTTTGGAACGTCCTGCATG - -AGCGGGACAACAA TGTGGCTTGAAGCGAAATT'TTGGAACGTCCTGCATG - -AGCGGGACAACAA TGTGGCTTGAAGTGAAATTTTGGAAMGTCCTGYRYR --AGCGGGACAACAA TGTGGCTTGAAGTAAAATTTTGGAACGTCCTGCATGTTTGTGGGACAATAA TGTGGCTTGAAGTAAAATTTTGGAACGTCCTGCATGTTTGTGGGACAATAA TGTGGCTTGAA ATGAAATTTTGGAAAGTCCTACATT - -AGTGGGACAACAA TGTGGCTTGAAGTAAAATTTTGGAACGTCCTGCTACTTAGCGGGACAACAA TGTGGCTTGAAGAAAAATTTTGGAACGTCCTGCTATATAGCGGGACAACATGTGGCTTGAAAATAAATTTTGGAACGCTTTGCCGTATGGCGAAGCACTTT

Table I. - 5S rDNA secpuence data matrix used for phylogenetic tree reconstruction. There are 161 nucleotide positions in this clata matrix. Forty-eight of the 161 sites $(30 \%)$ are informative. $("="=$ galp: Constant = invariable site: Uninf. = uninformative site as calculated by l'AuP 3.1. Underlined nucleotides are the spliced leader sequence) 


\section{RESULTS}

\section{DNA SEQUENCE COLLECTION AND ALIGNMENT}

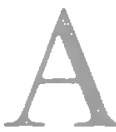

$t$ least two $5 S$ rDNA sequences were obtained for each species. Consensus sequences from each species were constructed and aligned to one another. The sequence data matrix which is the input for all of the tree reconstruction algorithms is shown in Table I. The Ascaris lumbricoides $5 \mathrm{~S}$ rDNA spacer region sequence (Nelsen et al., 1989) was included as the outgroup.

\section{PhylOGENETIC TREE RECONSTRUCTION}

1. Analysis by maximum parsimony methods (Swofford, 1993)

\section{Exhaustive search}

Due to the relatively large size of this data set, ten species representing all six genera were selected to undergo exhaustive search in PAUP 3.1.

Exhaustive search settings :

Branches having a maximum length of zero collapsed to yield polytomies; topological constraints were not enforced; trees were unrooted; multi-state taxa were interpreted as polymorphism ; character-state optimization was by accelerated transformation (reversals preferred)

Search results :

One shortest tree of length 121was found (Fig. 1) The statistics of the exhaustive search tree are the following (Kluge and Farris, 1969; Farris, 1989; Sanderson and Donoghue, 1989) : consistency index $(\mathrm{CI})=0.777$; $\mathrm{CI}$ excluding uninformative characters $=0.710$; CI expected $=0.684$; retention index $(\mathrm{RI})=0.690$; rescaled consistency index $(\mathrm{RC})=0.536$. The frequency distribution of tree lengths is shown in Figure 2.

\section{Branch-and-bound search}

Search settings :

An analysis of all sixteen ingroup species was undertaken with Ascaris lumbricoides as the outgroup species. Initial upper bound (upper limit of tree length) was unknown (to be computed via stepwise); addition sequence was set to furthest; branches having a maximum length of zero were collapsed to yield polytomies; topological constraints were not enforced; multi-state taxa were interpreted as polymorphism ; character-state optimization was by accelerated transformation.

Search results :

One shortest tree with length 198 was found in the branch-and-bound search (Fig. 3). The tree statistics are the following : consistency index $(\mathrm{CI})=0.758 ; \mathrm{CI}$ excluding uninformative characters $=0.624 ; \mathrm{CI}$ expected $=0.588$; retention index $(\mathrm{RI})=0.727$; rescaled consistency index $(\mathrm{RC})=0.551$.

2. Analyses by the neighbor-joining method (Saitou and Nei, 1987) and by the maximum likelihood method (Felsenstein, 1981)

Ascaris lumbricoides was used as the outgroup species in these analyses. The branching pattern of the shortest trees obtained was very similar to that of Figure 3, except that Loa loa and M. perstans form a group which switches position with the Onchocerca and D. immitis group in these analyses

3. Analysis by bootstrap methods (Felsenstein, 1985)

\section{Bootstrapping with parsimony analysis}

A total of 500 bootstrap replicates were analyzed using the parsimony algorithm. The strongly supported clades are the Onchocerca clade $(100 \%)$, the Bmigia-Wuchereria clade (97\%), the A. viteae and $L$. sigmodontis clade (97\%) and the Brigia clade (94\%). This tree is unable to resolve the branching order of the Brugia-Wuchereria clade, Loa loa, M. perstans, $D$. immitis and the Onchocerca clade (Fig. 4 and Table II).

\section{Bootstrapping with neighbor-joining analysis}

A total of 485 bootstrap replicates were analyzed. This analysis demonstrated that the Onchocerca clade (100\%), Brugia clade (99\%), Wuchereria clade (98\%) and Brugia-Wuchereria clade (99\%) were strongly supported by the data set (Fig. 4 and Table II).

\section{Bootstrapping with Maximum likelihood analysis}

A total of 100 replicates were examined. The Onchocerca clade (100\%) and the Brugia clade (94\%) were strongly supported (Fig. 4 and Table II).

\section{DISCUSSION}

\section{DNA SEQUENCE DATA COLLECTION AND SEQUENCE} ALIGNMENT

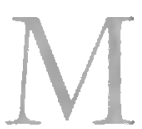
ost of the parasite materials were available in only limited quantities for this study. It was not practical to use traditional methods for extracting genomic DNA, endonuclease digestion, and cloning. A very effective method was cleveloped using PCR to amplify $5 \mathrm{~S}$ rDNA spacers and then to directly clone the PCR products. This method proved very efficient and reliable since the $B$. malayi $5 \mathrm{~S}$ 


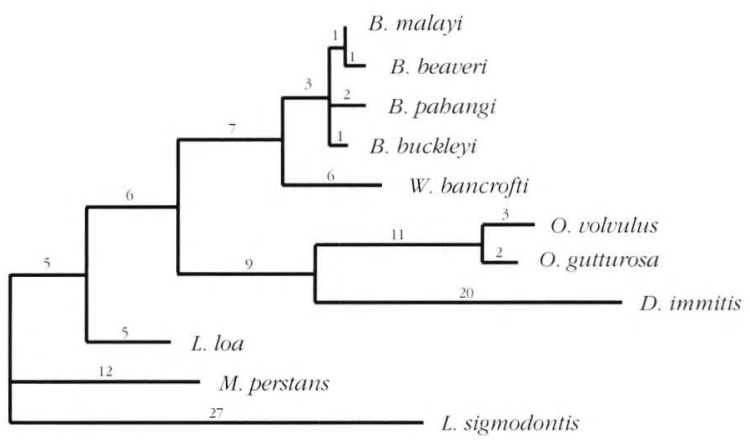

Fig. 1. - The tree found by exhaustive search. Tree length: 121 The numbers above each branch denote the branch length calculated by PALP 3.1

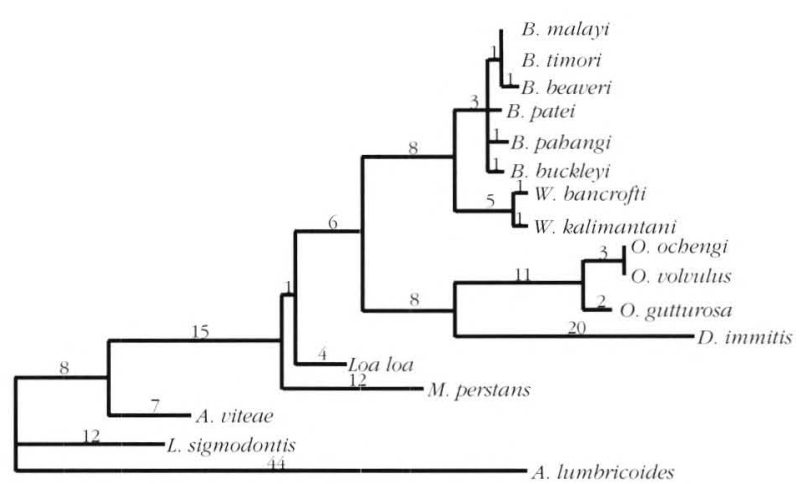

Fig. 3. - The branch-and-bound tree rooted by A. lumbricoides. Tree length: 198. This analysis showed that $A$. lumbricoides joins the tree at the L. sigmodontis branch

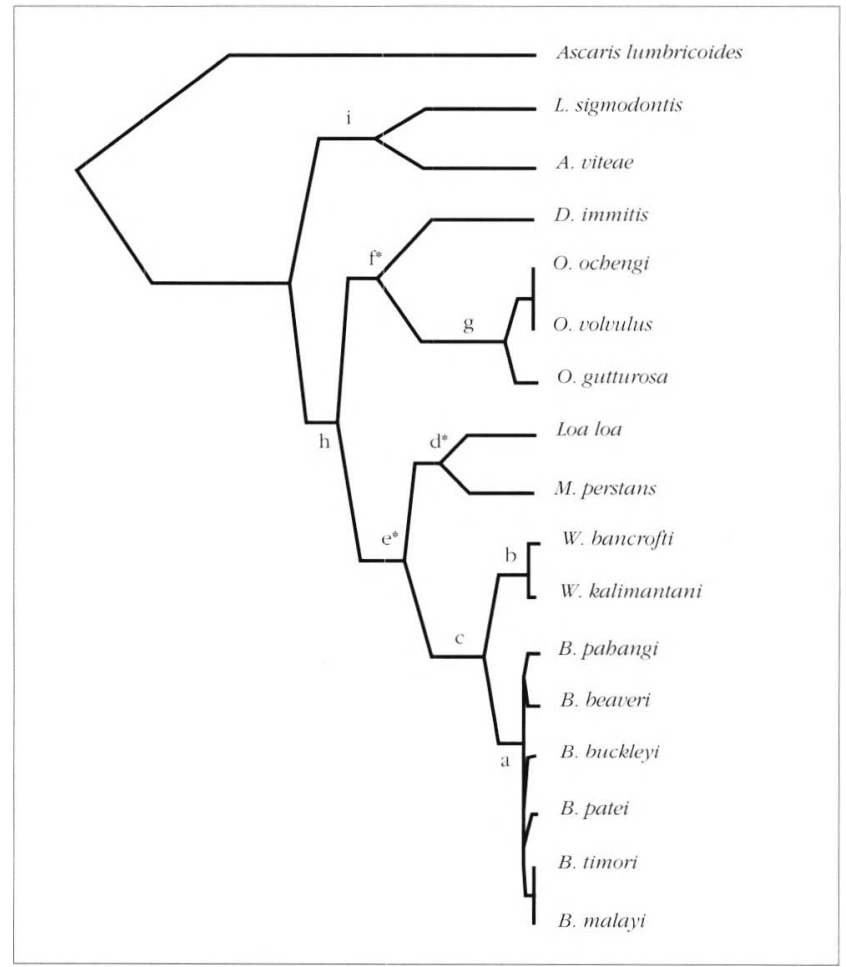

Fig. 4. - The basic bootstrapping pattern of the species studied in this paper. Small case letters denote the clades identified by the various bootstrap analyses. Clade names noted with an "inclicate low bootstrap values for those clades.
Fig. 2. - The frequency distribution of tree lengths of the $55 \mathrm{rIDNA}$ spacer sequences. A total of $34,459,425$ trees were evaluated. The mean tree length is 167 steps.

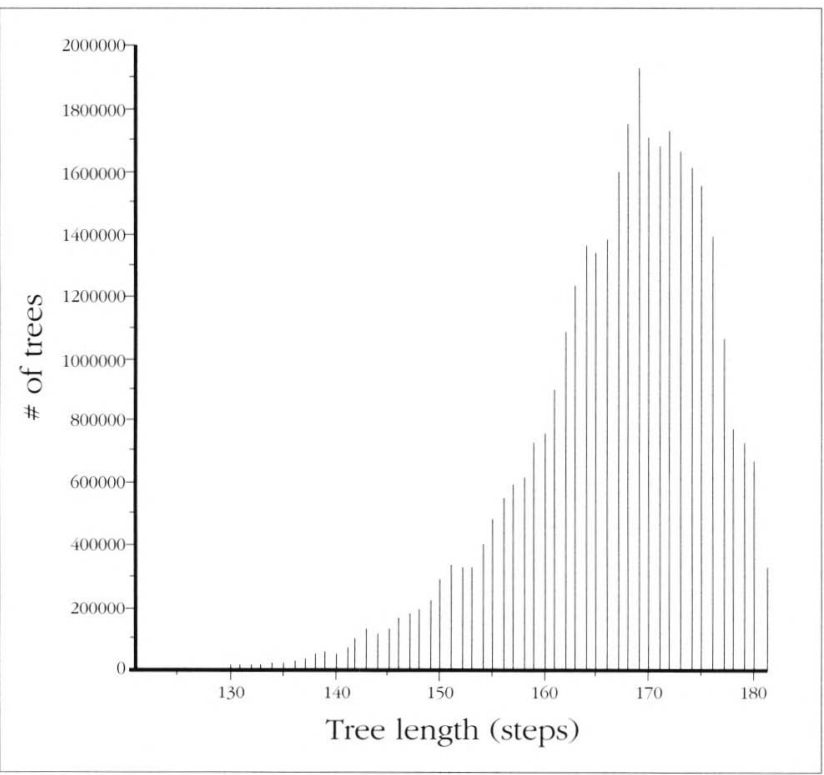

\begin{tabular}{|c|c|c|c|c|c|c|c|c|c|}
\hline Clade & $\mathrm{a}$ & b & c & $\mathrm{d}$ & e & f & $\mathrm{g}$ & h & $\mathrm{i}$ \\
\hline PA & $94 \%$ & $87 \%$ & $97 \%$ & $<50 \%$ & $<50 \%$ & $<50 \%$ & $100 \%$ & $97 \%$ & $97 \%$ \\
\hline NJ & $99 \%$ & $98 \%$ & $99 \%$ & $<40 \%$ & $40 \%$ & $69 \%$ & $100 \%$ & $85 \%$ & $85 \%$ \\
\hline ML & $94 \%$ & $76 \%$ & $91 \%$ & $<40 \%$ & $<40 \%$ & $<40 \%$ & $100 \%$ & $<40 \%$ & $92 \%$ \\
\hline
\end{tabular}


rDNA gene sequences obtained from PCR and clo ning were identical to the sequences in the literature which were collected by traditional genomic DNA cloning and sequencing methods.

The coding region sequence is virtually identical across the 16 species studied here (data not shown). On the contrary, the spacer region of the $5 S$ rDNA exhibited great length variations among the different species. They were as short as 400 nucleotides in Onchocerca species or as long as 600 nucleotides in some Brugia species. Even within the same species, there were sometimes different size classes of $5 \mathrm{~S}$ spacers. The spacer length heterogeneity is probably due to deletion and insertion events that have occurred cluring the evolution of these parasites. This phenomenon was confirmed by sequence comparison analysis. Sequence alignment is the first step in sequence comparison and phylogenetic reconstruction analysis. The 22-nucleoticle spliced leader region sequences were found in all of the filarial species studied (Table I). This conserved region was used as a focus for the sequence alignment.

\section{TREE RECONSTRUCTION ALGORITHMS}

Three main categories of methods of analysis were used in this study: parsimony, distance and maximum likelihood.

Parsimony analysis :

Branch-and-bound and exhaustive searches were performed in this analysis. Because the sequence region studied was the non-coding $5 \mathrm{~S}$ rDNA spacer region, all of the characters were equally weighted. Different sequence addition methods were tried and all gave the same topologies. The consistency indices were high (except in the exhaustive search, where some taxa were excluded) for the $5 \mathrm{~s}$ spacer region data set, indicating a low level of homoplasy in the spacer region. The $5 S$ spacer region data set showed a frequency distribution of tree length that is heavily skewed towards the end of long trees (Fig. 2), which is an indication of the phylogenetic information content in the data sets (Hillis, 1991). All of the parsimony analyses (some not shown) indicate that the Brugia clade and the Wuchereria clade are close neighbors. A. viteae and $L$. sigmodontis also form a clade, while the Onchocerca species form their own clade. Although the two shortest trees (Fig. 1 and Fig. 3) indicate that $D$. immitis and the Onchocerca clacle are closer to the Brugia-Wuchereria clade than are $M$. perstans and Loa loa, this relationship can be reversed with a cost of less than five steps (data not shown). In other words, parsimony analysis was unable to resolve the branching order of Loa loa, $M$. perstans, D. immitis and the Onchocerca clade (Table II). When D. immitis, which belongs to the Dirofilariinae subfamily and has a long branch length (this can cause problems in parsimony analysis), was excluded from the analysis, M. perstans and Loa loa appeared more closely related to the BrugiaWuchereria clade (data not shown). Parsimony analysis is very sensitive to unequal evolution rates in the branches due to parallelisms and reversals. This is especially a problem with long branches (Felsenstein, 1978; Lake, 1987). For closely related sequences, such as those studied in this paper, parallelisms and reversals should be rare. Therefore, the parsimony method can be considered reliable

Distance analysis :

Distance methods may not be accurate for distantly related sequences since the observed pairwise distances usually underestimate the true evolutionary distances due to homoplasy. Proper correction is needed in many cases to compensate for multiple-hits at a single site (Gojobori et al., 1990). Nei's (1991) computer simulation studies have shown that the neighborjoining method is superior to most of the other methods in retrieving the true tree under a variety of circumstances. Different distance methods were used in this study and they all gave similar branching patterns (data not shown). The neighbor-joining method also gave very high bootstrap values at some branches (Table II). It is interesting to note that D. immitis and the Onchocerca clade appeared in close proximity in most of the trees generated by different distance methods (data not shown). However, the bootstrap value for such groupings are low (Table II). The same is true for Loa loa, M. perstans and the WuchereriaBrugia clade. This phenomenon was observed in parsimony and maximum likelihood analysis as well.

Maximum likelihood analysis :

Maximum likelihood methods are not used as frequently as parsimony or distance methods because of the computational complexities of the former. The PHYLIP 3.5c program used on a SUN Sparc workstation greatly facilitated the computations. Maximum likelihood methods are the only ones that assume stochastic models of sequence evolution in which the user can specify rates of evolution at individual sites of the sequences. These methods are considered potentially the most reliable because of their statistical properties (Sidow and Wilson, 1991). In this study, the maximum likelihood method gave very similar branching patterns to those seen with other methods. Different transition/transversion ratios were used in various tree reconstructions. All ratios yielded very similar results (data not shown). 


\section{CONFIDENCE LIMITS ON PHYLOGENIES}

One of the statistical approaches used to assess confidence levels in phylogenetic hypotheses is the bootstrap analysis (Felsenstein, 1985). Bootstrap analysis is a method for the estimation of statistical error in situations where the underlying sampling distribution is difficult to assess (Efron, 1982 ; Efron and Gong, 1983). Instead of repeatedly sampling from the underlying distribution of taxonomic characters itself, which is often impractical, the bootstrap resamples the original data set to approximate the distribution. In this study, algorithms from all three major categories were applied to the bootstrapped clata sets (Table II). Taking all of the bootstrap results together, it is clear that the Brugia clade, the Wuchereria clade. the Brugia-Wuchereria clade and the Onchocera clade are strongly supported by the original data set. It was shown that confidence levels estimated by bootstrap analysis usually underestimates the real relationships among taxa (Sanderson, 1989). Some of the groups in this study did not reach a $95 \%$ confidence level by bootstrap analysis, but that does not necessarily mean these groupings should be discarded (Sanderson, 1989). The A. viteae-L. sigmodontis group had confidence levels ranging from $85 \%$ to $97 \%$ in the different bootstrap analyses, indicating a close relationship. The D.immitis-Onchocerca group appeared in the majority of trees generated by various methods in this study, although it had only at confidence level of $69 \%$ in the bootstrap analysis with the neighbor-joining method (data not shown, see previous discussion).

\section{THE HYPOTIIESIS}

It is very clear from analysis of the $5 \mathrm{~S}$ rldNA spacer sequence data and the above discussion, that there are at least four strongly supported clades: the Brugia clade, the Wuchereria clade, the BrugiaWucbereria clade and the Oncbocerca clade. The $A$. viteae and $L$. sigmodontis group is also strongly supported (97\%) in the bootstrap analysis using parsimony. Litomosoides has a long buccal capsule in the L3 and adult stages which is considered a very primitive character state (Anderson and Bain, 1976). The genus Acanthocheilonema has a developed buccal cavity and was considered the most primitive genus of the Dipetalonema line of the Onchocercinae subfamily (Chabaud and Bain, 1976). The outgroup Ascaris lumbricoides rooted most of the $5 \mathrm{~S}$ rDNA trees at the L. sigmodontis branch (except those trees clerived by algorithms which assume constant rates of evolution, data not shown). These observations are examples of congruence of molecular data with morphological data. The outgroup analyses also suggest that at least two subfamilies (Dirofilariinate and Onchocercinae) of the Onchocercidae family form a single natural group which does not exclude the suggestion of Bain (1981a).

In the Onchocerca clade, the 55 rDNA spacer sequence of $O$. volvulus is inclistinguishable from that of $O$. ochengi. It was suggested that $O$. volunlus belongs to a small line of Onchocerca in African Bovidae of the Savanna which is morphologically highly evolved (musculature atrophied and hypodermis hypertrophied in the females, Bain, 1981b). Chabaud (1981) recognized the capture phenomenon in parasite evolution. According to Chabaud, a captured parasite is defined as a parasite which, after becoming isolated in a new host, undergoes speciation and becomes morphologically distinct from the original species. O. volluhlus only infects humans while $O$. ochengi infects cattle. Morphological evolutionary studies indicated that $O$. volvulus and $O$. ochengi are the most closely related species in the genus Onchocerca. It is possible that $O$. volumlus evolved from the captured $O$. ochengi of the herbivore reservoir too recently for $O$. volvulus to show genetic distinctions from $O$. ochengi.

The two species in the Wuchereria clade are the only species that have been described for this genus. They form a natural group and are very closely related based on the INA sequence data in this study. $W$. bancrofti has a world-wide distribution and its only host is humans. while $W$. kalimantani is limited to South Kalimantan in Indonesia and infects monkeys. There is no correlation between morphological characters and geographical origin in W. bancrofti except at the microfilarial level (Schacher and Geddawi, 1969; Bain et al, 1985). 5s rDNA spacer region sequences of $W$. bancrofti from India, Egypt, Indonesia and Tahiti were analyzed and were identical to one another in this study (data not shown). Laurence (1989) placed the early infection of humans by $W$. bancrofti in Southeast Asia about 3,000 years ago based on historical records. He suggested that only through mass migration of human beings did Bancroftian filariasis become widely spread. It is possible that both species of Wuchereria originated from the same place in Indonesia and the speciation was completed long enough ago to allow the observation of differences at the DNA level as revealed in this study.

The bootstrap analyses of the $5 S$ rDNA spacer region sequence data demonstrated that Brugia and Wichereria are very closely related. These results are in very good agreement with morphological data (Buckley, 1958). For the six species studied in the Brugia clade, the 5 s rDNA spacer sequences alone 
were not sufficient to resolve the branching order. This fact. combined with the observation that $H h a$ I repeats are only present in Brigia. clearly indicates that Brugia is a natural group and that the species in this genus are very closely related (Xie, 1993).

The hypothesis for the phylogenetic relationships in the filarial parasite Onchocercidae family is illustrated in Figure 5. The use of $5 \mathrm{~s}$ rDNA spacer region sequences seems to confirm that the filarial parasites in this study ( filarial parasites of mammals) are recently derived, perhaps after the Spiruria went through a bottleneck in the Cretaceous disaster about 60 million years ago (Maggenti, 1983). In fact, the origin and speciation events of the Onchocerca genus in Africa may all be within the past 2.5 million years (during the Pleistocene epoch, Bain. 1981b). However. the filariae in the subfamily Oswalctofilariinate have a Gondwanian distribution which suggests their existence possibly as early as the late Jurassic period (about 120 million years ago, Bain, 1981).

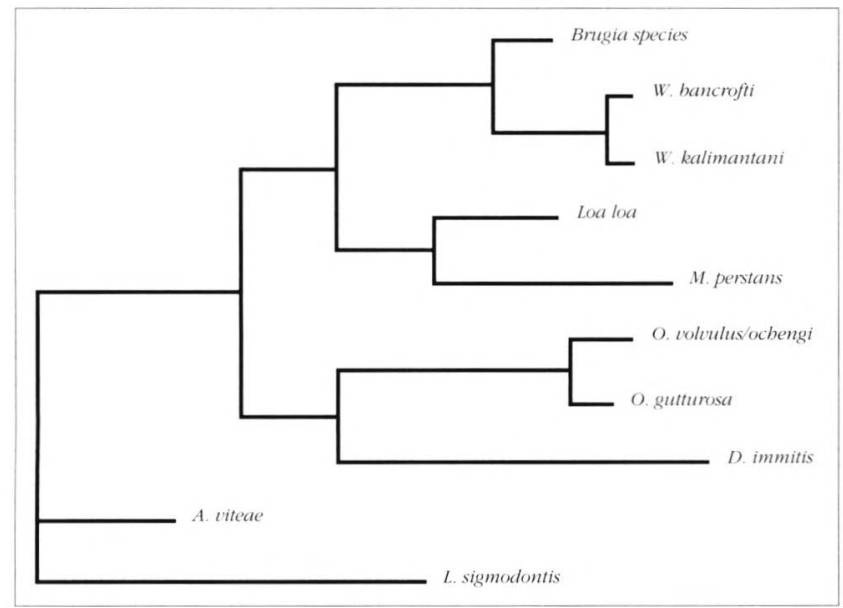

Fig. 5. - The proposed phylogenetic tree for the species studied in this paper. The six species in Bragia were lumped together in a single branch because their branching order is ambiguous based on is rRNA gene spalcer region secpuences alone

The only serious conflict between the results of this molecular phylogenetic study and the traditional morphology-based classifications is in the positions of two species: Loa loa and D. immitis. Based on morphological studies, they have been placed in the subfamily Dirofilariinae, yet they are not very close to each other in any of the DNA sequence-based phylogenetic trees. Morphologically, the L3 (third-stage larvae) of Loa loa does not resemble that of Dirofilaria. In this study, although the bootstrap value is low (Table II), D. immitis appeared in most of the trees generated by different methods to be closest to the Onchocerca clade (data not shown). These results correspond to certain aspects of the morphology of their L3 larvae (Bain and Chabaud. 1986). Based on these IDNA sequence data, Loa loa appeared to be closest to $M$. perstans and the Brugia-Wuchereria clade in most of the trees generated by various methods (data not shown). The bootstrap value is low, however, and morphologically the $\mathrm{L} 3$ of Loa loa and $M$. perstans are totally different. The Dirofilariinae subfamily is characterized by highly developed caudal alae and papillae while the Onchocercinae subfamily is characterized by a long. non-alate tail. Although some trees were rooted at the D. immitis branch (data not shown) which might support D. immitis as a clifferent subfamily, the position of $L o a$ loa in all of the trees generated by all of the different methods suggest its close connection with the Onchocercinae subfamily. These molecular data question the constitution of the Dirofilariinale subfamily.

\section{ACKNOWLEDGMENTS}

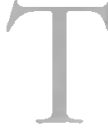

he authors wish to thank J. McCall. U.R. Raro, A.C. Vickery, T.C. Orihel, A.S. Dissanaike, L.A. McReynolds, F. Partono, S.E.O. Meredith, T.B. Nutman. E.A. Ottesen and T.R. Unnasch for providing the parasite materials used in this study; J. Felsenstein and D.L. Swofford for technical assistance with their computer programs: Dr. Pierre Darlu for his constructive suggestions in the preparation of this manuscript and his help in writing the French translation of the abstract. Support for this study was provided by the Blakeslee fund for genetics research at Smith College.

\section{REFERENCES}

ANIDRSON R.C. and BAIN O. : Keys to genera of the Order Spirurida. Part 3. Diplotriaenoidea. Aproctoidea and Filarioidea. "CIH Keys to the Nematode Parasites of Vertebrates" No. 3 (R. C. Anderson, A. G. Chabaud and S. M. Willmote, Eds). Publisher : Commonwealth Agricultural Bureaux, Farnham Royal, Bucks, England, 1976

Ash L.R. and LiTTL: M.D) : Brigia beaceri sp. n. (Nematoda : Filarioideal) from the raccoon (Procyon lotor) in Louisiana. J. Parasit.. 1964, 50.119-123

Bain O. : Filariids and their evolution. Parasitologl, 1981a. 82 (part 4), 167-168

BAIN O. : Le genre Onchocerca: Hypothèses sur son évolution et clé dichotomique des espèces (The genus Onchocerca : hypothesis on its evolution and a key to the species). Ann. Parasitol. Hum. Comp. 1981b. 56. $503-526$

BaIN O. and Chaba(1) A.G. : Atlas des larves infestantes de Filaires. Trop. Med. Parasit., 1986, 37, 301-340.

Bain O., Dissanalke A.S., Cross J.H., Harinaslta C. and Sicharit S. : Morphologie de Wuchereria bancrofit 
adulte et sub-adulte. Recherche de caractères différenticls entre les souches. Ann. Parasitol. Hum. Comp. 1985. 60. 613-630.

ButCKi.H. J.J.C. and EDEsON J.F.B. : On the adult morphology of Wucbereria sp. (malayi) from a Monkey (Hacaca irus) and from cats in Nalaya, and on Wuchereria pahangi n.sp. from a dog and a cat. J. Helmintbology, 1956, XXX. 1-20

Buchiey I.J.C. Nelson G.S. and Heiscll R.B. : On Wucherevia patei n.sp. from the lymphatics of cats, dogs and genet cats on Pate island. Kenya. J. Helmintbology: 1958. XXXII, 73-80

Chamalid A.g. and Bain O. : La lignée Dipetalonema. Ann. Parasitol. Hum. Comp. 1976, 51, 365-397.

Chamald A.G. and Choptet. M.T. : Nourel essai de classification des filaires (super-famille des Filarioidea). Ann Parasit., 1953, 28, 172-192.

Chabat' A.G. : Host range and evolution of nematode parasites of vertebrates. Parasitolog), 1981, 82 (part 4), $169-174$.

EFron B. : Nonparametric standard errors and confidence intervals. Can. J. Stat., 1981, 9, 139-172.

EFron B. : The jackknife, the bootstrap, and other resampling plans. CBMS-NSF Regional Conference Series in Applied Mathematics, Monograph 38. Society of Industry and Applied Mathematics. Philadelphia. 1982.

EFron B. and Gong G. : A leisure look at the bootstrap. jackknife, and cross validation. Am. Stat., 1983. 37, 36-48

FARRIs I.S. : The retention index and the rescaled consistency inclex. Cladistics, 1989, 5, 417-419

Felsenstein J. : Cases in which parsimony or compatibility methods will be positively misleading. Sy'st. Zool., 1978 27. $401-410$

Felsenstrin J. : Evolutionary trees from 1)NA sequences : a maximum likelihood approach. I. Mol. Evol.. 1981. 17. 368-376.

Felsenstein J. : Confidence limits on phylogenies : An approach using the bootstrap. Evolution, 1985. 39, 783-791.

Felsenstein J. : Phylogenetic Inference Programs (PHYLIP), Manual 3.5c. University of Washington, Seattle. 1993.

Fitci W. M. : Towards defining the course of evolution : Minimal change for a specific tree topology. Syst. Zool., 1971, 20, 406-416.

Freedman D.J. : Molecular evolutionary stuclies of filarial parasites of the genus Brugia. Ph. D Thesis. Lniversity of Massachusetts at Amherst, 1991.

Gojobori T. Mortyama E.N. and Kimtra M. : Statistical methods for estimating sequence divergence in Molecular Evolution : computer analysis of protein and nucleic acid sequences. (eclited by R. F. Doolittle). pp. 531-550. Methods in Enzymology, vol. 183. Academic Press, New York, 1990

Gonzalez I.L., Sylvester J.E., SMITh T.F. Sta.ibolian D. and Schmickel. R.D. : Ribosomal RNA gene sequences and hominoid plyylogeny. Mol. Biol. Evol, 1990, 7, 203-219.

Hillis D,M. : Discriminating between phylogenetic signal and random noise in DNA sequences in phylogenetic Analysis of INA Sequences (eclited by Miyamoto, M. M. and Cracraft, J.) pp 278-294. Oxford University Press.
New York, 1991

KifMS J. and GARRETT R.A. : Secondary structural elements exclusive to the sequences flanking ribosomal RNAs lend support to the monophyletic nature of the archaebacteria. J. Mol. Evol., 1990, 31, 25-32.

KLIGE A.G. and FArris J.S. Q Quantitative phyletics and the evolution of the anurans. Syst. Zool., 1969, 18, 1-32.

LAKE J.A. : A rate-independent technique for analysis of nucleic acid sequences: evolutionary parsimony. Hol. Biol. Evol., 1987, 4, 167-191.

Lat ReNCE B.R. : The global dispersal of Bancroftian filariasis. Parasitolog)' Toda1, 1989, 5, 260-264.

Magganti A.R. : Nematode higher classification as influenced by species and family concepts in Concepts in nematode systematics (Edited by Stone, A. R.: H. M. Platt and L. F. Khalil) pp. 25-40. Academic Press, New York, 1983.

MCI`TYRE C.L., Clakki: B.C. and Appfls R. : INA sequence analyses of the ribosomal spacer regions in the Triticeale. Plant Syst. Evol., 1988, 160,91-104.

Ner M. : Relative efficiencies of different tree-making methods for molecular data in Phylogenetic Analysis of I) NA Sequences (edited by Miyamoto, M.M. and Cracraft, J. ) pp. 90-128. Oxford University Press, New York. 1991

Netsox D.W and Honja B.M. : Genes coding for $5 \mathrm{~S}$ ribosomal RNA of the nematode Caenorbabditis elegans. Gene. 1985, 38, 245-251.

Nelisi. T.W., Shambal Gh J., Denker J., Chubb G., Faser C. PI TNAM L. and BENNETT K. : Characterization and expression of a spliced leacler RNA in the parasitic nematode Ascaris lumbricoides var. suum. Hol. Cell. Biol. 1989, 9 3543-3547.

Palmiliki J. R., PlRnomo D. T. Dennis, and H. A. Marwoto Filarid parasites of South Kalimantan (Borneo) Indonesia Wuchereria kalimantani sp. n. (Nematoda: Filarioidea) from the silvered leaf monkey, Presbytis cristatus Eschischoltz 1921. J. Parasit. 1980, 66, 645-651

PARTONO F. PURNOMO, IDFNNIS D.T., ATMOSORDJONO $\mathrm{S}$.

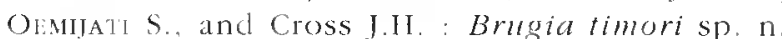
(Nematoda: Filarioidea) from Flores island, Inclonesia. I. Parasit., 1977, 63, 540-546.

Ransolioff R.M., Denkfr J.A., Takacs A.M., Hannon G.J. and NILSEN T.W: : Organization and expression of 5 S rRNA genes in the parasitic nematode, Brigia malayi. Nucleic Acids Research, 1989, 17.3773-3782.

Sanderson M.J. : Confidence limits on phylogenies : the bootstrap revisited. Cladistics, 1989, 5, 113-129

SAITot N. and Nei M. : The neighbor-joining method : a new method for reconstructing phylogenetic trees. Wol. Biol. Evol., 1987, 4, 406-425.

SANDERSON M.J. and DONOGHE M.J. : Patterns of variation in levels of homoplasy. Evohtion. 1989, 43, 1781-1795.

SChachitr J.F. and Gednawi M.K. : An analysis of speciation and evolution in Wuchereria bancrofti by the study of nuclear constancy (eutely) in microfilariae. Ann. Trop Med. Parasitol., 1969, 63,67-82.

Sidow A. and Wilson A.C. : Compositional statistics evaluated by computer simulations in Phylogenetic Analysis of DNA Sequences (edited by Miyamoto, M. M. and Cracraft. J.) pp. 129-146. Oxford University Press, New York. 1991 
SwOFFORD, D.L, and Olsen G.J. : Phylogeny reconstruction in Molecular Systematics (edited by Hillis, D. M. and C. Moritz) pp. 411-501. Sinauer Associates, Massachusetts, 1990

SwoFforD D.L. : Phylogenetic Analysis Using Parsimony, version 3.1 Computer program distributed by the Illinois Natural History Survey, Champaign. Illinois, 1993.

Verbeet M.P., van Heerikhuizen H., Klootwijk J., Fontijn R.D. and Planta R.J. : Evolution of yeast ribosomal DNA : molecular cloning of the rDNA units of Kluyveromyces lactis and Hansenula wingei and their comparison with the rDNA units of other Saccharomycetoideae. Mol. Gen. Genet., 1984, 195, 116-125.

WeIr E.E. : A revised classification of the nematode superfamily Filarioidea. Proc. Helm. Soc., Wash.. 1935, 2, 8488.

XIE II. : Molecular phylogenetic studies on filarial parasites. Ph. D Thesis. University of Massachusetts at Amherst, 1993

Yokota Y., Kawata T., Ima Y., Kato A. and Tanifun S. : Nucleotide sequences of the $5.8 \mathrm{~S}$ rRNA gene and internal transcribed spacer regions in carrot and broad bean ribosomal DNA. J. Mol. Evol., 1989, 29, 294-301.

Accepté le 17 mars 1994 